\title{
Elever har ojämn kunskap om tekniska system
}

Gunnar Höst

Tekniska system finns nästan överallt i samhället, men det är ett område som innehåller utmaningar för undervisningen. I en ny studie beskriver forskare hur elevers nivåer av kunskap varierar inom olika aspekter av tekniska system. En slutsats är att det kan vara värt för lärare att satsa på områden med särskilda utmaningar, till exempel deras syften och styrning, och andra aspekter av tekniska system som inte syns.

Överallt omkring oss människor finns tekniska lösningar som människan skapat för att hjälpa oss med våra behov och problem. Många av dessa lösningar är svåra att överblicka eftersom de består av ett stort antal delar som samverkar. Det är inte heller alltid klart var gränserna för lösningarna går. Sådan teknik kallas tekniska system, och exempel på det kan vara allt från en telefon och elsystemet i ett hus till globala industriella processer.

I en studie har forskare från Linköpings och Göteborgs universitet undersökt vilken typ av kunskap elever i årskurs 8 har om tekniska system [1]. Eleverna i studien fick svara på frågor om vatten och avlopp i ett hus (Figur 1). Det visade sig att de kunde mycket om vissa aspekter av systemet, till exempel strukturen, men de kunde mindre om andra aspekter, såsom systemets gräns.

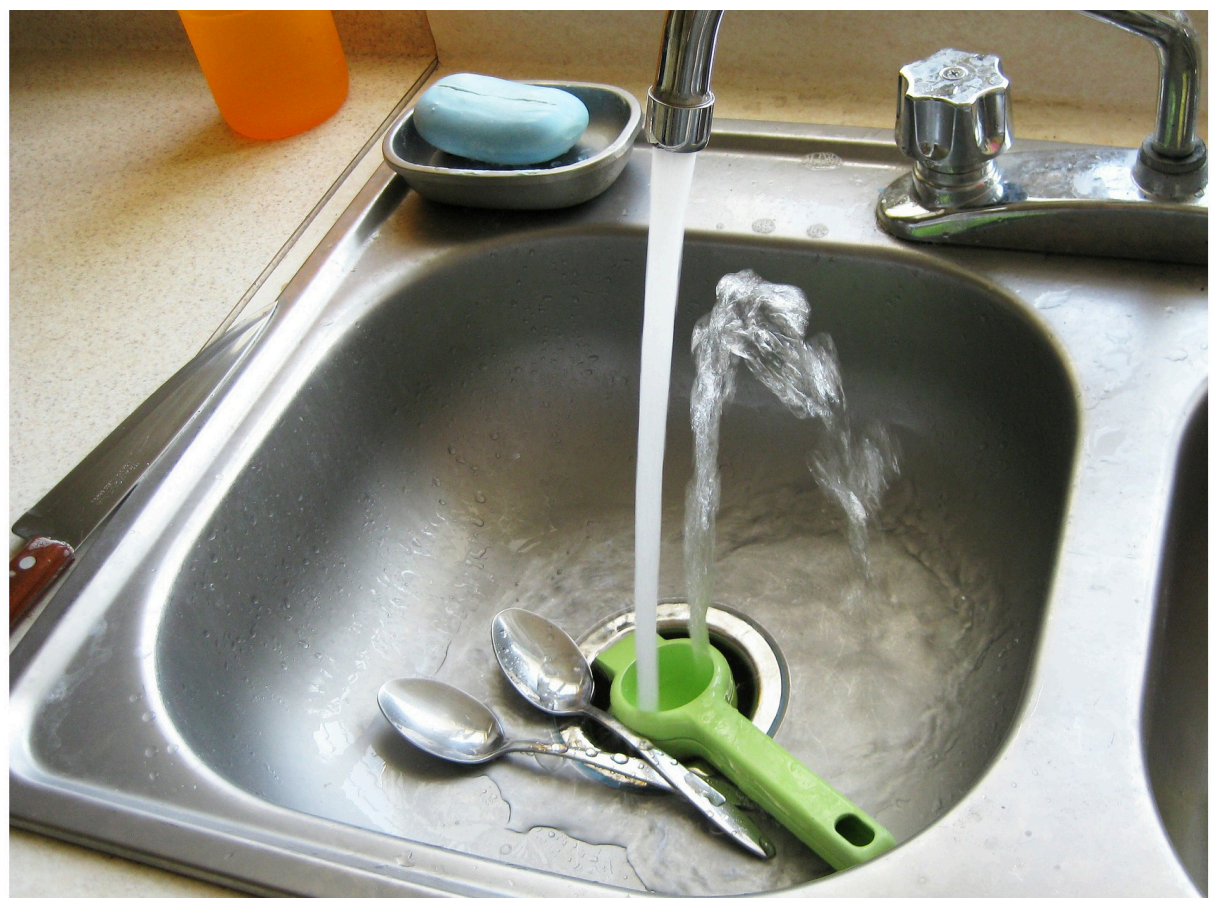

Figur 1. Eleverna i studien fick svara på frågor om vatten och avlopp i ett hus. 
Testet gjorde det också möjligt för forskarna att särskilja olika nivåer i elevernas kunskap, något som skulle kunna bli användbart för tekniklärare, enligt forskaren Jonas Hallström.

- I studien har vi bedömt komplexiteten i elevernas kunskaper om tekniska system, vilket vi i framtida studier hoppas kunna utveckla till en kunskapstypologi och bedömningskriterier för kunskaper om tekniska system, säger han.

\section{Test visar elevers kunskap om tekniska system}

Forskarna delade upp kunskap om tekniska system i fyra olika aspekter. Dessa var:

- systemets gräns mot omgivningen

- $\quad$ systemets syfte

- systemets struktur och beteende

- flöden av resurser i systemet.

Enligt forskarna kompletterar de fyra aspekterna varandra, och alla krävs för en god förståelse av ett tekniskt system.

Eleverna fick svara på frågor som var gjorda för att fånga upp de olika aspekterna. Testet innehöll en bild av ett hus, med pilar som visade att vatten gick både in i och ut ur huset. De fick svara på frågor som till exempel:

- Vad är färskvattensystemet till för? (Handlar om systemets syfte.)

- Påverkar färskvattensystemet miljön, och i så fall hur? (Handlar om systemets gräns mot omgivningen.)

- Hur fungerar färskvattensystemet? (Handlar om alla fyra aspekterna.)

Eleverna fyllde i testet i grupper om tre elever. Sedan analyserade forskarna det eleverna skrivit och ritat för att se vilka aspekter de tog upp.

Inom varje aspekt kan elever visa olika nivåer av kunskap. Forskarna kallar detta kunskapskvaliteter eftersom de skiljer sig åt kvalitativt. För att kunna bedöma detta formulerade forskarna för var och en av aspekterna tre till fem olika kunskapskvaliteter. Dessa kvaliteter utgör en hierarki, där en lägre nivå ligger till grund för en högre nivå. Till exempel innehöll aspekten "systemets struktur och beteende" fem olika nivåer:

1. Ge exempel på komponenter.

2. Beskriv relationer mellan komponenter.

3. Koppla komponenter till systemets beteende.

4. Beskriv systemet med någon relevant modell (till exempel nätverks- eller cyklisk modell).

5. Beskriv hur förändringar i komponenter påverkar andra komponenter och systemets syfte.

\section{God kunskap om systemets struktur och beteende}

När det gäller systemets struktur och beteende visade det sig att de flesta kunde ge exempel på komponenter i vattensystemet och kopplingar mellan dessa. Nästa nivå av kunskap var mycket mindre vanlig i svaren. Eleverna gav alltså inte mycket förklaring till hur systemets delar är kopplade till dess övergripande beteende. Exempel på sådana förklaringar skulle kunna vara att ett vattentorn gör så att det hela tiden finns tryck så att vatten kan flöda in i huset.

På en högre nivå av kunskapskvalitet, enligt forskarnas nivåindelning, förväntades eleverna beskriva systemet med en modell. Det visade sig att fler elever gjorde detta jämfört med föregående nivå där de skulle koppla delarna till systemets beteende. Modellerna var över lag 
ganska enkla, och de flesta beskrev sina modeller genom att rita hur systemets olika delar hänger ihop.

Någon grupp gav en verbal modell, där de beskrev systemet genom att göra en analogi med blodflödet. I denna modell fungerade vattentornet som hjärta. Bara en grupp lyckades nå den högsta nivån, där de skulle beskriva hur förändringar i systemets delar påverkar dels systemets övriga delar och dels dess syfte.

\section{Svårare med osynliga aspekter av tekniska system}

Det var få elever som tydligt nämnde något om systemets gräns mot omgivningen. De som ändå gjorde det trodde felaktigt att vattnet gick från avloppet via ett reningsverk direkt tillbaka som färskvatten. Även det tekniska systemets syfte visade sig vara svårt att formulera. De flesta elever la fokus på vad vattnet som kom in i huset skulle användas till. Däremot var det ovanligt att de tog upp syftet med att leda ut avloppet. De exempel som fanns handlade om toaletter.

De flesta elever beskrev flödet av vatten, vilket förstås inte var förvånande. Det var däremot få elever som beskrev flöden med en mer avancerad kunskapskvalitet. Dessa nivåer av kunskap handlar om flöden av energi och information, hur dessa flöden används i systemet, samt information som används för kontroll av systemet. Till exempel skulle det kunna handla om att varmvatten leder energi in i huset, eller att information om förbrukningen av vatten används för att styra hur mycket vatten som ska föras in i systemet.

Resultaten stämmer med tidigare forskning om vad elever kan om tekniska system. Det är vanligt att elever har en relativt god förståelse för systemens struktur, alltså vilka delar ett tekniskt system består av och hur dessa är länkade med varandra. Även in- och utflöden brukar elever ha kunskap om, alltså till exempel att vatten leds in i ett hus och att avloppsvatten leds ut. Däremot brukar det vara svårare att förstå dess gräns mot omgivningen, flöden av information och hur systemet kontrolleras, samt vilken roll människan har i systemet.

\section{Mer forskning om tekniska system i teknikämnet}

I studien uppger de 32 elever som deltog att de inte arbetat med tekniska system i undervisningen. Det innebär att det inte var underligt att de inte hade så djupa kunskaper om vatten- och avloppssystemet i ett hus. Enligt forskarna visar det ändå att många elever i studien utifrån tidigare erfarenheter hade en viss förståelse för denna typ av hushållsnära system. Det visar på att det kan vara värt att fokusera mer på det som är svårt, menar Jonas Hallström.

- En lärare skulle kunna ta fasta på just de "osynliga" delarna eller aspekterna av tekniska system, till exempel hur ett specifikt system ser ut under ytan, eller hur det styrs genom återkoppling, och undervisa om det. Elever behöver också få lära sig mer om hur olika komponenter fungerar, säger han.

Forskarna ser studien som ett första steg mot en taxonomi för elevers kunskap om tekniska system. En sådan taxonomi skulle innehålla en utveckling av den beskrivning av nivåer av kunskap som de använde i den här studien. Det skulle i sin tur kunna ge stöd för lärares bedömning i teknikämnet.

Artikeln presenterades på konferensen PATT, vilket är den största forskningskonferensen inom teknikdidaktik. Namnet står för Pupils' Attitudes Toward Technology, eftersom den från början hade fokus på just attityder till teknik. Numer är konferensen mycket bredare och tar upp all typ av teknikdidaktisk forskning. Vid konferensen presenterades även andra artiklar om tekniska system [2-4]. Se även [5]. 


\section{Notering}

Författaren har skrivit denna artikel som en del av ett uppdrag från Skolverket. Artikeln publicerades först på Skolverkets hemsida för forskningsspridning:

https://www.skolverket.se/skolutveckling/forskning-och-utvarderingar/artiklar-om-forskning/eleverhar-ojamn-kunskap-om-tekniska-system

\section{Referenser}

1. Hallström J, Klasander C, Zetterqvist A. Towards a Student Systems Thinking Inventory: Defining 'Qualities of Knowledge'about Technological Systems. Techne serien-Forskning i slöjdpedagogik och slöjdvetenskap. 2021;28(2):196-203.

2. Dagan O. Student Teachers' Mental Models of Everyday Control Systems - The Sensors that Operate the Door. Techne serien - Forskning i slöjdpedagogik och slöjdvetenskap. 2021;28(2):62-71.

3. Hallström J. Evaluating an Intervention to Improve Secondary Pre-Service Teachers' Conceptions of Feedback in Technological Systems. Techne serien -Forskning i slöjdpedagogik och slöjdvetenskap. 2021;28(2):204-12.

4. Engström S, Norström P, Söderberg H. A Model for Teaching Systems Thinking: A Tool for Analysing Technology Teachers' Conceptualising of Systems Thinking, and How it is Described in Technology Textbooks for Compulsory School. Techne serien - Forskning i slöjdpedagogik och slöjdvetenskap. 2021;28(2):241-5.

5. Hallström J, Klasander C. Making the invisible visible: Pedagogies related to teaching and learning about technological systems. I: Pedagogy for Technology Education in Secondary Schools. Cham: Springer; 2020. 